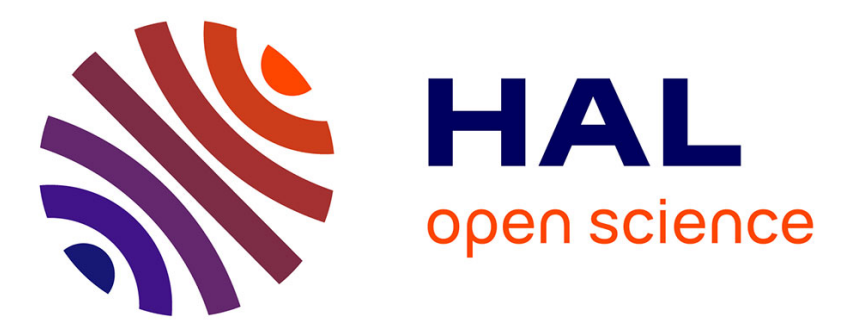

\title{
MICROSTRUCTURE OF HARD FERRITES AND THEIR MAGNETIC PROPERTIES \\ F. Esper
}

\section{To cite this version:}

F. Esper. MICROSTRUCTURE OF HARD FERRITES AND THEIR MAGNETIC PROPERTIES. Journal de Physique Colloques, 1977, 38 (C1), pp.C1-69-C1-72. 10.1051/jphyscol:1977114 . jpa00216973

\section{HAL Id: jpa-00216973 https://hal.science/jpa-00216973}

Submitted on 1 Jan 1977

HAL is a multi-disciplinary open access archive for the deposit and dissemination of scientific research documents, whether they are published or not. The documents may come from teaching and research institutions in France or abroad, or from public or private research centers.
L'archive ouverte pluridisciplinaire HAL, est destinée au dépôt et à la diffusion de documents scientifiques de niveau recherche, publiés ou non, émanant des établissements d'enseignement et de recherche français ou étrangers, des laboratoires publics ou privés. 


\title{
MICROSTRUCTURE OF HARD FERRITES AND THEIR MAGNETIC PROPERTIES
}

\author{
F. J. ESPER \\ Robert Bosch GmbH., Materials Research Department, Stuttgart, West Germany
}

\begin{abstract}
Résumé. - Les aimants en ferrites durs sont utilisés d'une façon importante dans la technologie. Selon les applications auxquelles ils sont destinés ils doivent avoir des propriétés différentes. II faut pour cela que le fabricant ait la possibilité de tester leurs propriétés et d'influer d'une manière simple sur la production. Il est possible de tirer des conclusions sur les propriétés magnétiques à partir de la microstructure. De plus il existe une corrélation entre la microstructure et certains paramètres de production. C'est pourquoi on a pu, en testant la microstructure, controller la production de ferrites durs et par là même les propriétés magnétiques.

Enfin on fait quelques remarques sur la préparation des micrographies.
\end{abstract}

\begin{abstract}
Hard ferrite magnets are used in the technology to a significant extend. According to their various applications they have to have different properties. The manufacturer should thus have the possibility to test their properties and to control the production of these magnets in a simple way. It is possible to draw conclusions from the microstructure on the magnetic properties. Furthermore a correlation exists between manufacture parameters and microstructure. So testing the microstructure of the hard ferrites allows control of the manufacturing process and by this way of the magnetic properties. Some remarks are made upon the preparation of the micrographs.
\end{abstract}

1. Introduction. - The hard ferrites have gained a great significance in the technology during the last decade. New applications were found for these ceramic permanent magnets. In most small dc-motors the wire wound field was replaced by the permanent field of hard ferrites, but the permanent magnets had to meet special requirements and this means that they must have special properties. The variations or tolerances of these magnetic properties were limited partially very narrowly. Therefore it is necessary to know the correlation between manufacturing parameters and the magnetic properties. Microstructure investigation is a very helpful way to clarify these correlations.

2. Experimental. - Hard ferrites belong to the ceramic materials [1, 2]. In spite of their special mechanical properties - i. e. brittleness etc. - micrographs of ceramic specimens can be produced in exactly the same way as those of metallic specimens inasmuch as a plane surface is produced by mechanical abrasion.

A diamond impregnated wheel is used to cut slices; a moderate cutting pressure and good cooling being necessary. As with metals the mounting medium chosen is a cold setting resin or a similar material under pressure and elevated temperatures in order to avoid rounding off the edges. Since these materials are generally softer than the ceramic it may be necessary to introduce a hard constituent into the mounting material, i. e. small $\mathrm{Al}_{2} \mathrm{O}_{3}$-spheres, which material is offered by specialist firms. Grinding of the mounted specimens is then possible on a surface grinder using diamond wheels (grain size D 70 bronze mounted) with light pressure and low feed rate.

Fine polishing can be undertaken by hand on polishing tables or on rotating wheels (250 to $700 \mathrm{rpm}$ ) with the usual silicon carbide papers. For the final polishing $\mathrm{Al}_{2} \mathrm{O}_{3}$-pastes with grain sizes of $15 \mu \mathrm{m}$, $7 \mu \mathrm{m}, 3 \mu \mathrm{m}$ and sometimes also even $1 \mu \mathrm{m}$ are used on the normal polishing machines.

Chemical etching as employed with metals is not a satisfactory method of revealing the microstructure of hard ferrites. Thermal etching is the best method. The well polished specimen is heated in air to $100^{\circ}$ through $150^{\circ} \mathrm{C}$ below the sintering temperature for about 30 to 60 minutes.

3. Microstructure and magnetic properties. - It is well known that the isotropic and anisotropic hard ferrites are distinguished by the alignment of the small hexagonal crystals they consist of. In the isotropic magnets the crystals are arranged randomly, whereas in the anisotropic magnets there is a strong orientation of the crystals. According to this the demagnetization curves of the two kinds of magnetic materials differ from each other (Fig. 1). The demagnetization curve and the microstructure picture at the bottom right characterize an isotropic barium or strontium ferrite. The two pictures on the top at the right show the microstructure of an anisotropic strontium ferrite. On the right the microstructure shown is 


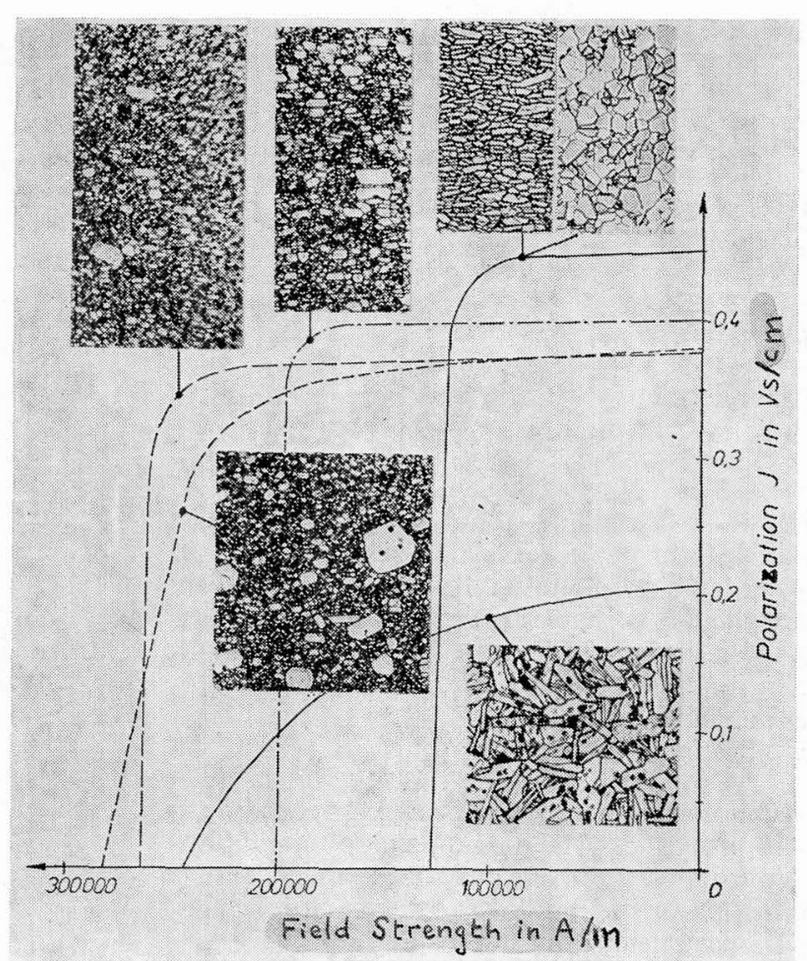

FIG. 1. - Demagnetization curves of various hard ferrites with characteristic micrographs of the microstructure (X 1000).

perpendicular to the magnetic field, applied during compaction of the magnet and on the left the magnetic field is in the plane of the micrograph from top to bottom.

The microstructure consists of coarse hexagonal particles, which are aligned very strongly, thus causing a high remanence, but due to the relatively large crystal size the value of the coercivity is low $[3,4,5]$.

A comparison of the two other upper pictures reveals the influence of the microstructure on the coercivity. The left hand picture shows a practically uniform structure with fine grains whereas the microstructure of the central picture although coarser also shows a relatively uniform distribution of grain sizes.

The specimen with the fine structure has a significantly higher coercivity than that with the coarser structure.

It should be emphasized however that in both cases the rectangular shape of the demagnetization curve is caused by the relatively uniform grain size distribution of the specimens. This is illustrated by a comparison with the shortly dashed demagnetization curve: Although remanence and coercivity are comparable with the values for the broken demagnetization curve the microstructure is different as shown by the lower micrograph on the left. The structure is fine-grained but there are too many coarse grains to be neglected. These are responsible for the flattening off of the demagnetization curve. This flattening off of the demagnetization curve can have a deleterious influence on the stability of dynamically applied magnetic circuits such as in small dc-motors or generators.
4. Manufacture parameters and microstructure. We have shown that a correlation exists between microstructure and magnetic properties. Furthermore there is also a correlation between manufacture parameters and the microstructure of the hard ferrites as will be shown subsequently.

In our experiments the calcination temperature of the blended raw materials $\left(1075^{\circ} \mathrm{C}\right.$ and $\left.1300^{\circ} \mathrm{C}\right)$ and the milling time of the calcined material $(1.5 \mathrm{~h}$ and $6 \mathrm{~h}$ ) were chosen as manufacture parameters.

The magnets were compacted in a magnetic field and sintered at $1220^{\circ} \mathrm{C}$. All the powders, milled for $1.5 \mathrm{~h}$ were densified to $4.7 \mathrm{~g} / \mathrm{cm}^{3}$ by the sintering process and the powders milled for $6 \mathrm{~h}$ to $4.8 \mathrm{~g} / \mathrm{cm}^{3}$.

In table $I$ the results for the magnetic values are given.

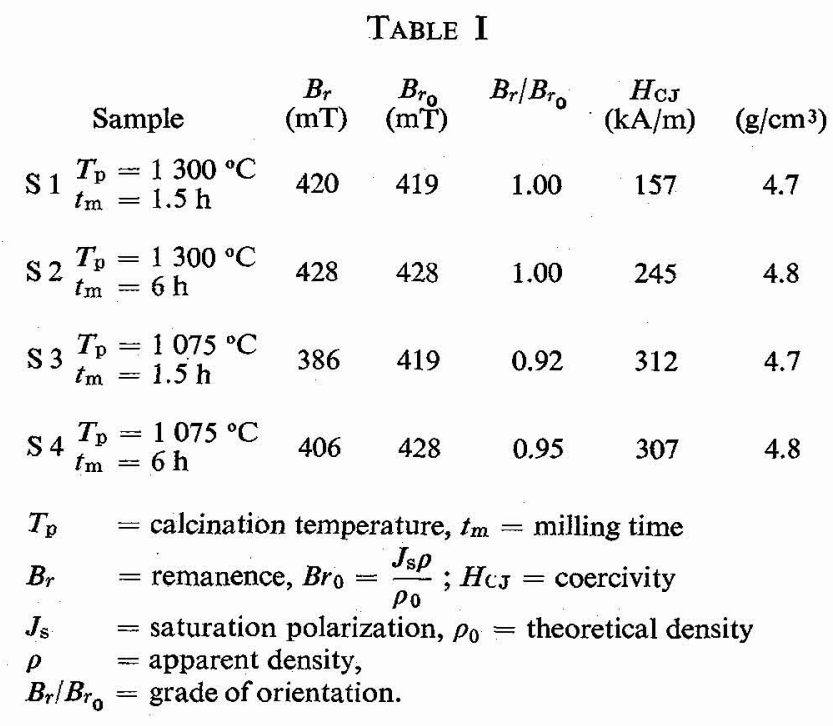

From table $I$ it can be seen that the samples $S_{1}$ and $S_{2}$, calcined at $1200^{\circ} \mathrm{C}$ have a grade of orientation of about 1. That means, all particles are oriented almost exactly. The remanence can be improved only by increasing the apparent density. However the two samples, distinguished by their milling time, have very different coercivities.

The samples $\mathrm{S}_{3}$ and $\mathrm{S}_{4}$, calcined at only $1075^{\circ} \mathrm{C}$, have a lower grade of orientation and, according to this, lower values of the remanence. The coercivity on the other hand has significantly higher values for the samples with low calcination temperature; the influence of the milling time on $H_{\mathrm{CJ}}$ however is very small for these samples.

Figure 2 shows the microstructure and the demagnetization curves $S_{1}$ and $S_{2}$. The microstructure of $S_{1}$ (coarse milling) consists of crystals with a nearly uniform size. The mean crystal size is 3-5 $\mu \mathrm{m}$ with a maximum size of $10 \mu \mathrm{m}$. It can be seen that the crystals are aligned well, corresponding to the high grade of orientation. The low coercivity is caused by the relatively large crystal size. The demagnetization curve has a sharply rectangular shape. 


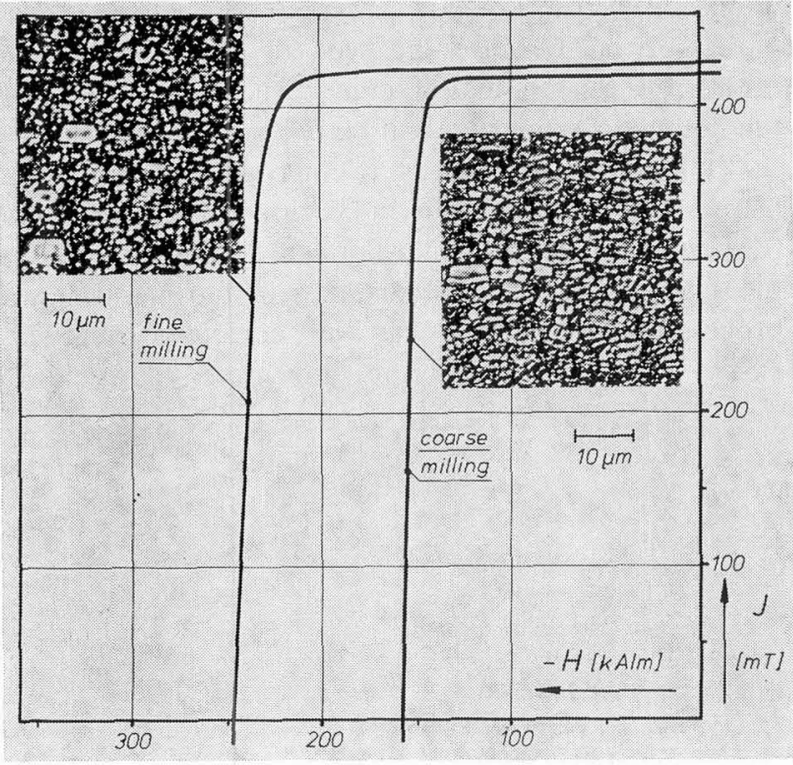

FIG. 2. - Micrographs and demagnetization curves of anisotropic $\mathrm{Sr}$-ferrites calcined at $1300^{\circ} \mathrm{C}$ for a milling time of $1.5 \mathrm{~h}$ and $6 \mathrm{~h}$ resp.

The mean crystal size of $S_{2}$ (fine milling) is smaller than that of $S_{1}$. It is about $1 \mu \mathrm{m}$ causing a coercivity of more than $245 \mathrm{kA} / \mathrm{m}$. Due to an irregular crystal growth during the sintering process the microstructure of $\mathrm{S}_{2}$ is characterized by an inhomogeneous crystal size, influencing to a small extend the shape of the demagnetization curve. The crystals are aligned well, too.

Figure 3 gives the microstructure and the demagnetization curves of the samples $S_{3}$ and $S_{4}$. Because of the lower calcination temperature the mean crystal size is smaller than $1 \mu \mathrm{m}$. The crystal size is near to the

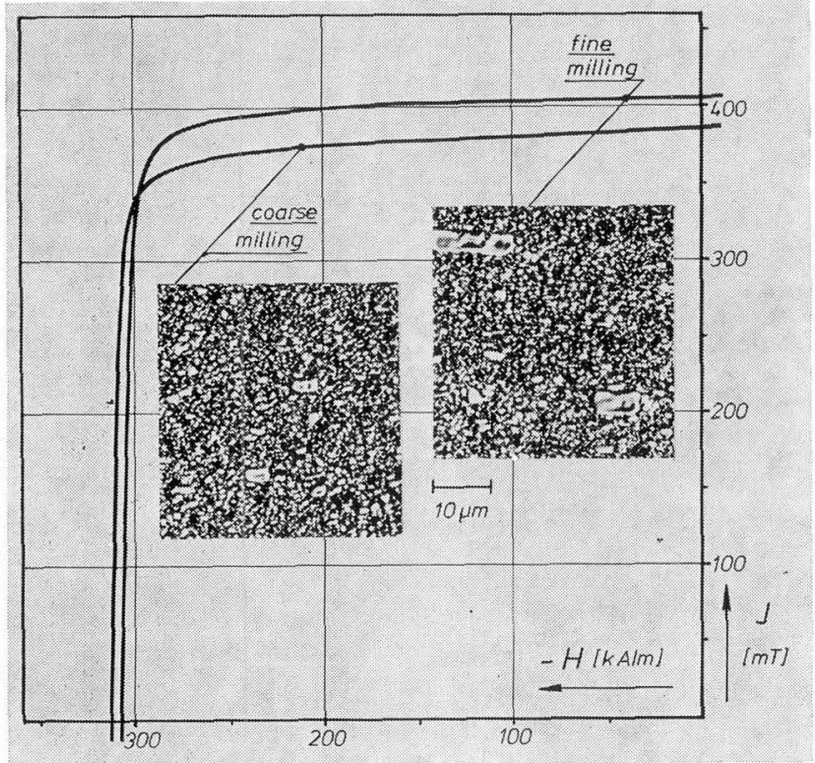

FIG. 3. - Micrographs and demagnetization curves of anisotropic Sr-ferrites calcined at $1075^{\circ} \mathrm{C}$ for a milling time of $1.5 \mathrm{~h}$ and $6 \mathrm{~h}$ resp. resolving power of the microscope. Therefore it is difficult to recognize the ultimate crystals and their orientation. The fact that the grade of orientation increases with increasing milling time indicates that the agglomerates of the calcined material are not totally disintegrated when milled for $1.5 \mathrm{~h}$.

The microstructure of the sample $S_{3}$ (coarse milling) is again very uniform. From the small particle size a high coercivity can be expected and the demagnetization curve should be nearly rectangular. The microstructure of $S_{4}$ (fine milling) is very similar to $S_{3}$. In contrast to $S_{3}$ some large crystals can be seen, indicating also that this sample tends to an irregular grain growth. From this it can be inferred that it is necessary to find a balance between the required magnetic properties, the duration of milling and the sintering process. In figure 4 the micrographs of three topotactical barium ferrites are reproduced together with their demagnetization curves. The topotactical process is a special procedure for manufacturing hard ferrites.

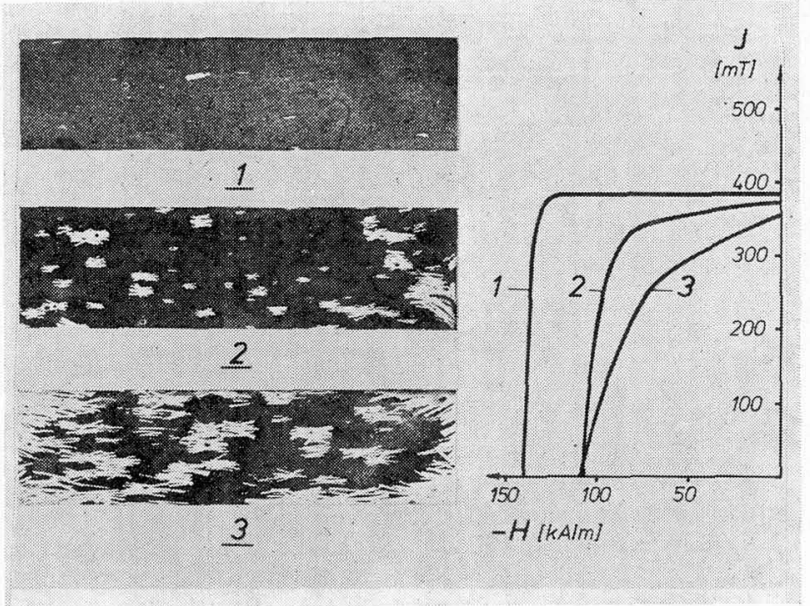

FIG. 4. - Micrographs and demagnetization curves of topotaccally produced hard ferrites.

An iron oxide or mainly an iron hydroxide with rodlike particles is mixed with barium carbonate. The mixture is compacted without the application of a magnetic field. The orientation of the rodlike iron oxide particles is performed only by mechanical means.

During the sintering process the iron oxide particles react with the barium oxide and hexagonal crystals with a magnetic anisotropy are formed, showing the same orientation as that of the iron oxide particles before sintering. Because the orientation of the iron oxide particles is relatively poor compared with the alignment of the barium ferrite crystals oriented by applying a magnetic field, the alignment has to be improved by the sintering process. As is well known, the well oriented crystals grow at the expense of the misoriented ones. Therefore a controlled grain growth has to be induced. But it is very difficult to find a good 
compromise between high remanence values and still acceptable values of the coercivity due to the grain growth. This material tends to an irregular grain growth causing very large particles due to inhomogenious densification by the compacting process. The effect of this irregular grain growth on the microstructure and the magnetic properties can be seen in figure 4.

5. Conclusion. - There is a close correlation bet- ween microstructure and magnetic properties of the hard ferrites. Because the type of microstructure is influenced by the manufacture process, its effect on the magnetic properties can be recognized by studying the microstructure. Thus a micrograph of a hard ferrite gives not only an indication on the magnetic properties but also of what happened especially during the sintering process. If mistakes in the manufacture process occured, they can be corrected relatively easily, if the micrograph is interpreted correctly.

\section{References}

[1] Esper, F. J., Heimke, G., Practical Metallography 13 (1976) 122-137.

[2] Esper, F. J., HeimKe, G., Sonderbände der praktischen Metallographie Band 6 "Metallographie-Schadensanalyse und Werkstoffentwicklung» (1976) 243-258.

[3] Went, J. J., Rathenau, G. W., Gorter, E. W., Van OosTERHOUT, G. W., Philips Techn. Rev. 13 (1952) 194.

[4] Rathenau, G. W., Smir, J., Stuiuts, A. L., Z. Phys., 133 (1952) 250.

[5] Sixtus, K. J., Kronenderg, K. J., Tenzer, R. K., J. Appl. Phys. 27 (1956) 1051. 